\title{
A Rare Case of Sudden Death in a Patient with Takotsubo Cardiomyopathy Secondary to Cardiac Rupture
}

\author{
Tarun Dalia (D), ${ }^{1}$ Bashar S. Amr, ${ }^{2}$ Ankit Agrawal (D), ${ }^{3}$ Archana Gautam, \\ Venkata Rakesh Sethapati, ${ }^{5}$ and Jared Kvapil ${ }^{2}$ \\ ${ }^{1}$ Internal Medicine, University of Kansas Medical Center, Kansas City, KS 66160, USA \\ ${ }^{2}$ Department of Cardiovascular Medicine, University of Kansas Medical Center, Kansas City, KS 66160, USA \\ ${ }^{3}$ Internal Medicine Residency Program, Rutgers Robert Wood Johnson Medical School-Saint Peter's University Hospital, \\ New Brunswick, NJ 08901, USA \\ ${ }^{4}$ Montgomery Internal Medicine Residency Program, University of Alabama, Montgomery, Alabama 36116, USA \\ ${ }^{5}$ Department of Pathology \& Laboratory Medicine, University of Kansas Medical Center, Kansas City, KS 66160, USA
}

Correspondence should be addressed to Tarun Dalia; tdalia2@kumc.edu

Received 2 February 2019; Revised 18 June 2019; Accepted 4 July 2019; Published 25 July 2019

Academic Editor: Antonio de Padua Mansur

Copyright (C) 2019 Tarun Dalia et al. This is an open access article distributed under the Creative Commons Attribution License, which permits unrestricted use, distribution, and reproduction in any medium, provided the original work is properly cited.

Takotsubo cardiomyopathy (TCM), also known as broken heart syndrome or stress-induced cardiomyopathy, is a rare condition with an estimated incidence of $0.02 \%$ of all hospitalizations in United States and $2 \%$ of all acute coronary syndrome presentations. TCM predominately presents as a transient wall motion abnormality of the left ventricular apex due to emotional or physical stress. Cardiac rupture in the setting of TCM is an extremely rare phenomenon with limited published case reports. We present a case of a 75-year-old female who had cardiac rupture secondary to TCM and performed a literature review using Ovid MEDLINE for published cases showing this association. After the literature review, we found 20 cases showing this association, which are listed in a tabular fashion.

\section{Introduction}

Takotsubo cardiomyopathy (TCM), also known as stressinduced cardiomyopathy, was first described in Japan in 1990 [1]. It mimics acute coronary syndrome and is characterized by transient systolic and diastolic dysfunction of the left ventricle, wall motion abnormalities, and elevated cardiac biomarkers and is frequently preceded by emotional or physical stress [2]. Ballooning of the left ventricular apex with a finding of patent coronary arteries is typically present on left ventriculography and cardiac catheterization, respectively. It is diagnosed in $0.02 \%$ of all nationwide hospitalization and predominantly involves elderly females [3]. The inpatient mortality rate in patients with TCM is $4.5 \%$ [3]. There has been a gradual increase in the incidence of TCM with the realization that this entity is not as benign as it was thought to be. As per recent TCM registry, on long-term follow-up, rate of major adverse cardiac and cerebrovascular events was $9.9 \%$ per patient-year and death was $5.6 \%$ per patientyear [4]. While TCM is usually reversible, it may present with rare complications including systemic embolism, life-threatening ventricular arrhythmias, cardiogenic shock, and cardiac rupture leading to cardiac arrest [5]. We present an exceptional rare case of TCM leading to left ventricular wall rupture. To the best of our knowledge, only 20 cases have been reported so far showing this very rare outcome.

\section{Case Presentation}

A 75-year-old female with past medical history of coronary artery disease, hypertension, hyperlipidemia, paroxysmal atrial fibrillation, systemic lupus erythematosus, and deep venous thrombosis was transferred from an outside hospital for the management of non-ST segment elevation myocardial infarction (NSTEMI). The patient presented to the local emergency department with substernal chest pain radiating 


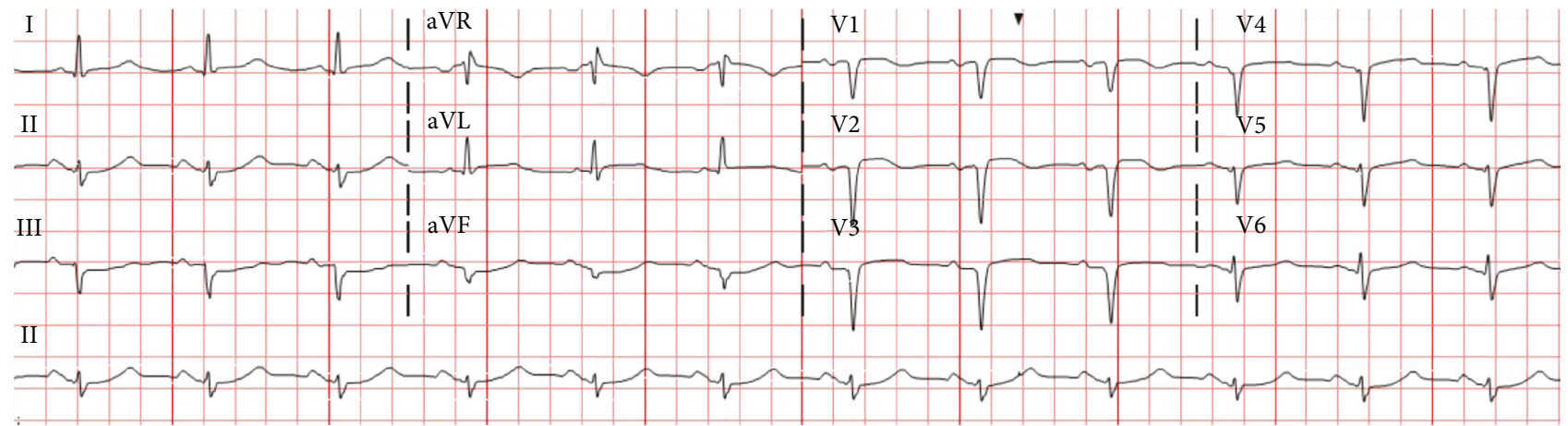

FIGURE 1: Electrocardiogram showing sinus rhythm at 74 beats/min, left axis deviation, Q waves in V1 to V3, 1 mm ST segment elevation of $\mathrm{V} 2-\mathrm{V} 3$, and poor $\mathrm{R}$ wave progression.

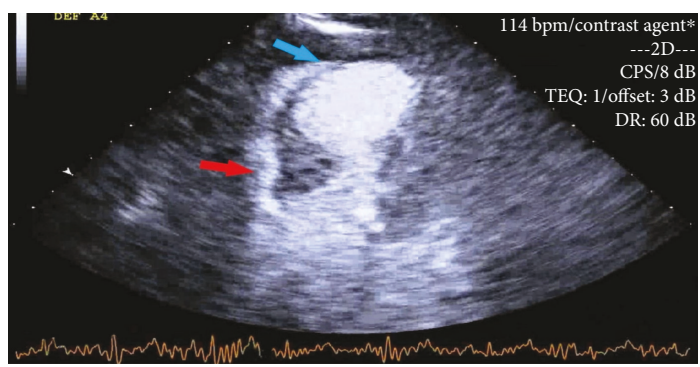

FIGURE 2: Transthoracic echo showing severely reduced ejection fraction of $30-35 \%$, severe hypokinesis of mid to apical segment with more involvement of the mid anteroseptum, and anterior wall (blue arrow) with basal hyperkinesia and basal asymmetric hypertrophy of the septum (red arrow).

to the left jaw and arm and was found to have an elevated troponin $(0.26 \mathrm{ng} / \mathrm{ml})$. She was appropriately given aspirin, heparin, and nitroglycerine and was transferred to our medical centre for further care. On presentation, she was alert and oriented, her blood pressure was 200/100 $\mathrm{mmHg}$, nontachycardic, nontachypneic, and sating at $97-98 \%$ on 2 litres per minute of oxygen. Pertinent physical exam findings include bibasilar crackles, no murmurs/rubs, normal heart sounds, and no pedal edema. Pertinent laboratory values include haemoglobin $(14.2 \mathrm{gm} / \mathrm{dl})$, platelet count $(191 \mathrm{k} / \mu \mathrm{l})$, white count $(14.4 \mathrm{k} / \mu \mathrm{l})$, INR $(1.1)$, creatinine $(0.66 \mathrm{mg} / \mathrm{dl})$, and AST $(87 \mu / 1)$. Electrocardiogram (ECG) on presentation showed sinus rhythm at 74 beats/min, left axis deviation, Q waves in V1 to V3, $1 \mathrm{~mm}$ ST segment elevation of V2-V3 (present in prior ECG), and poor $\mathrm{R}$ wave progression (Figure 1). A resting 2D Doppler echocardiogram was performed on admission which showed severely reduced ejection fraction of $30-35 \%$, severe hypokinesis of mid to apical segment with more involvement of the mid anteroseptum, and anterior wall with basal hyperkinesia and basal asymmetric hypertrophy of the septum (Figure 2).

The decision was made to undergo urgent cardiac catheterization as her chest pain continued to worsen while on nitroglycerine drip, and the troponin on arrival to our facility was elevated $(6.80 \mathrm{ng} / \mathrm{ml})$. While in the elevator, en route to the cardiac catheterization laboratory, the patient became

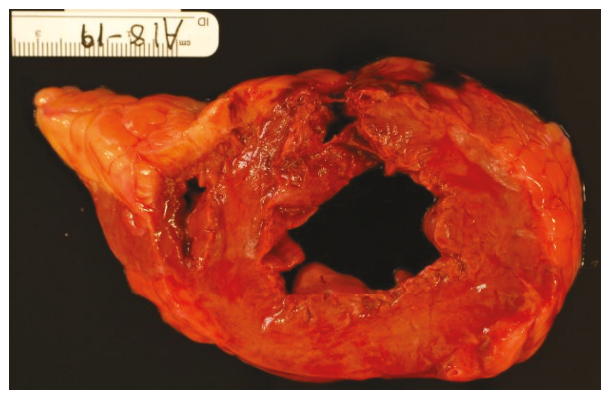

FIgURe 3: Gross pathology. A cut section of the left ventricle showing an anteriorly located, transmural slit-like rupture $(1 \mathrm{~cm} \times 0.8 \mathrm{~cm})$ of the ventricular wall.

unresponsive. Resuscitation was immediately started, labs at the time of code blue were significant for acute drop in haemoglobin from 14.2 to 6.2 , hypokalaemia of $2.5 \mathrm{mmol} / \mathrm{l}$, and arterial blood gas showed metabolic acidosis $(\mathrm{pH}$ of $7.27, \mathrm{pCO} 2$ of $34, \mathrm{pO} 2$ of 28 , bicarbonate of $15.2 \mathrm{mmol} / \mathrm{l}$ ). The catheterization team was unable to establish arterial access hence coronary catheterization was not performed. Unfortunately, despite after aggressive resuscitative efforts for 50 minutes, the patient died.

Autopsy was performed and revealed $1000 \mathrm{ml}$ of blood in chest wall cavity. Gross pathology revealed a slit-like rupture of $1 \mathrm{~cm} \times 0.8 \mathrm{~cm}$, transmural and located anteriorly $1.5 \mathrm{~cm}$ inferior to the base of the heart. The pericardial surface was smooth and tan red in colour (Figure 3). Microscopically, this area had coagulative necrosis, hypereosinophilic appearance of myocytes with abundant ghost cells (cells without nuclei), and cells with pyknotic nuclei. The neutrophilic infiltrate, haemorrhage, and contraction band necrosis can also be visualised (Figure 4). Sacha et al. reported similar rupture site changes indicative of new acute infarct and transmyocardial necrosis leading to rupture in TCM patient [6]. There was epicardial haemorrhage $(3.5 \mathrm{~cm}$ in length) adjacent to the left anterior descending artery proximal to the site of rupture. Sections in this area revealed area of infarction with early signs of mottling grossly. Interestingly, this area lacked neutrophils suggesting an area of infarction of less than 10 hours. We speculated that this difference in timeline could be due to 


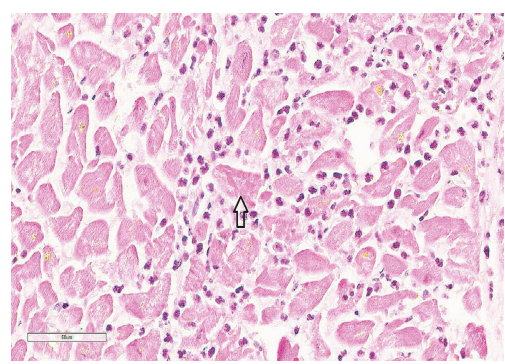

(a)

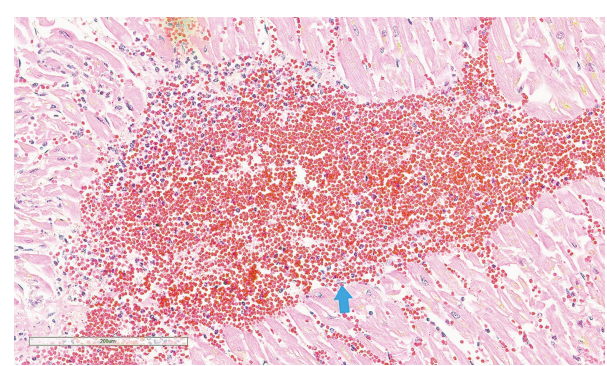

(b)

Figure 4: (a) Microscopic pathology. Acute myocardial infarction, H\&E, 400x. Note: neutrophilic infiltration of the myocardium, with contraction bands (arrow). (b) Myocardium, H\&E, 400x, showing intraventricular haemorrhage (blue arrow).
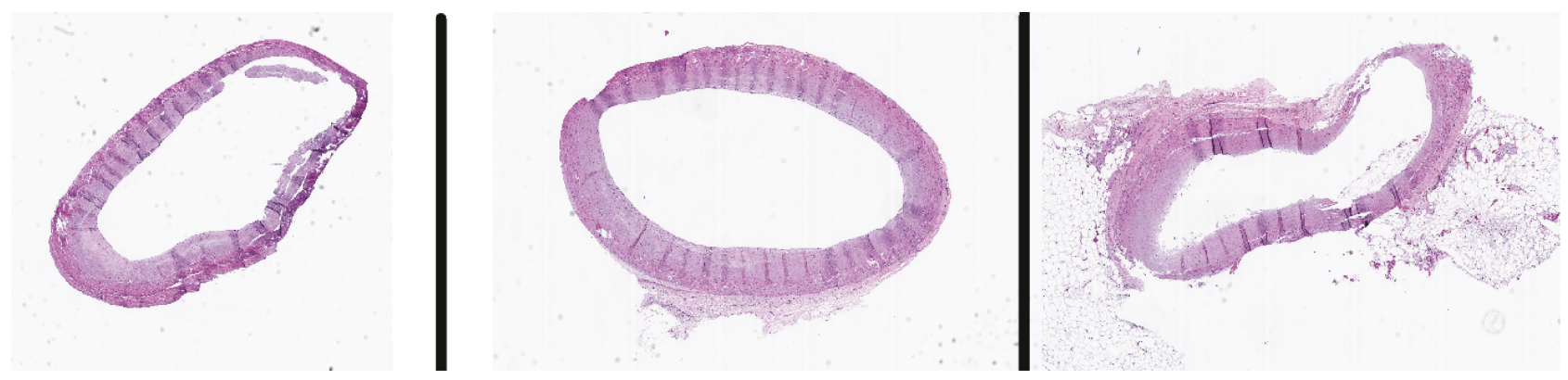

FIGURE 5: Cut sections of coronary arteries showing patent arteries with minimal atherosclerosis.

the discordance of myocardial contraction seen between the apex and base which is often seen in TCM. Most importantly, her major coronary arteries were patent with minimal atherosclerosis and without evidence of organizing thrombus (Figure 5), supporting the histopathological criteria for the diagnosis of TCM.

\section{Discussion}

TCM is generally classified by an acute and profound but reversible left ventricular dysfunction in the absence of significant coronary artery disease. The revised Mayo criteria are most commonly used currently to establish diagnosis of TCM which includes combination of clinical presentation, ECG, transthoracic echo, and angiographic finding [7]. It is often triggered by an acute emotional or physical stress [4]. TCM is associated with a catecholamine surge and adrenoceptor hyperactivity which can increase the cardiotoxicity leading to increased chances of complications. Increased levels of norepinephrine in the state of stress can cause localized ventricular wall motion abnormalities and ST segment changes [8]. In our case, we believe the rupture of the left ventricular wall was multifactorial and a consequence of increased afterload due to elevated blood pressure, probable increased catecholamine surge, and adrenoceptor hyperactivity in the setting of acute stress.

As per Kumar et al., the characteristics of patients with cardiac rupture in TCM when compared to patients with TCM who did not had cardiac rupture include the following: female gender, older age group, higher systolic and diastolic blood pressure, higher frequency of ST elevations in inferior lead, low ejection fraction (EF), and higher left ventricular peak systolic fraction [9]. Our patient portrayed a number of these characteristics including older age, female gender, higher systolic and diastolic pressures, and severely reduced EF.

As histopathological slides from our patient showed no thrombus and minimal atherosclerosis of coronary arteries, our case falls into the newly diagnosed category of MINOCA (myocardial infarction with nonobstructive coronary arteries). TCM is one of the categories of MINOCA; other categories include coronary spasm, coronary dissection, plaque disruption, spontaneous coronary emboli, myocarditis, and coronary microvasculature dysfunction [10]. Our pathological findings were classical for TCM, and apart from the area of rupture, no other area of infarction was seen. Although coronary spasm can also lead to infarction and subsequent death, hence we cannot exclude it definitively, but when our patient's histological slides are taken in consideration with clinical scenario, TCM is the more likely diagnosis.

A thorough literature review of 20 previous cases of TCM complicated with cardiac rupture is listed in Table 1. The characteristics of these patients include 95\% females and mean age of 74.9 years. 16 patients presented with chest pain or discomfort (76\%); 17 had ST segment elevations $(81 \%)$; only 9 cases mentioned troponin levels and out of these, 8 showed increased troponin (89\%). These findings further support that TCM mimics acute myocardial infarction. Including our case, a total of 17 patients died (81\%). The location of rupture was reported in ten cases; six at the apex (60\%), two involving the anterior wall (20\%), and two involving the posterior wall (20\%). 


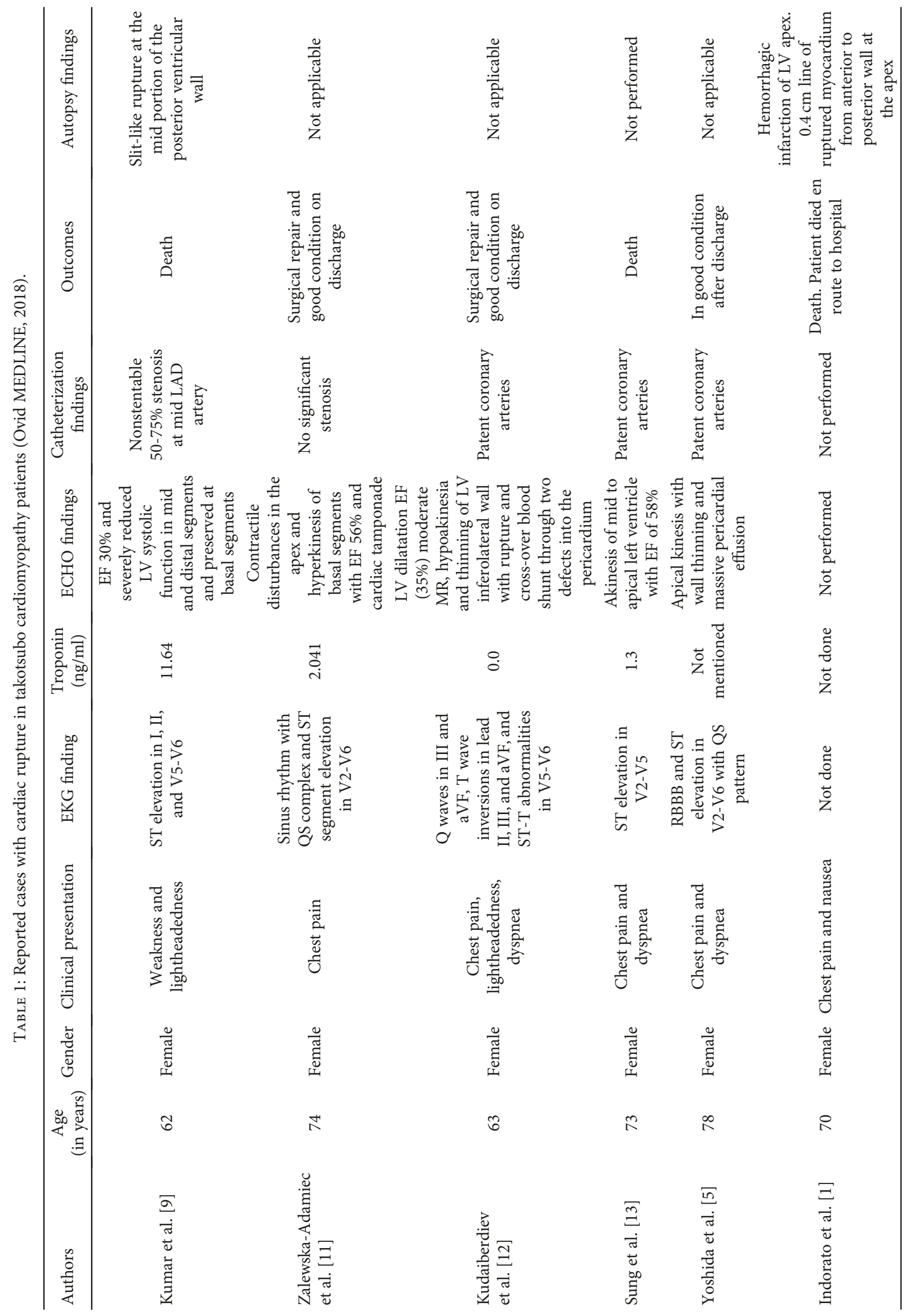




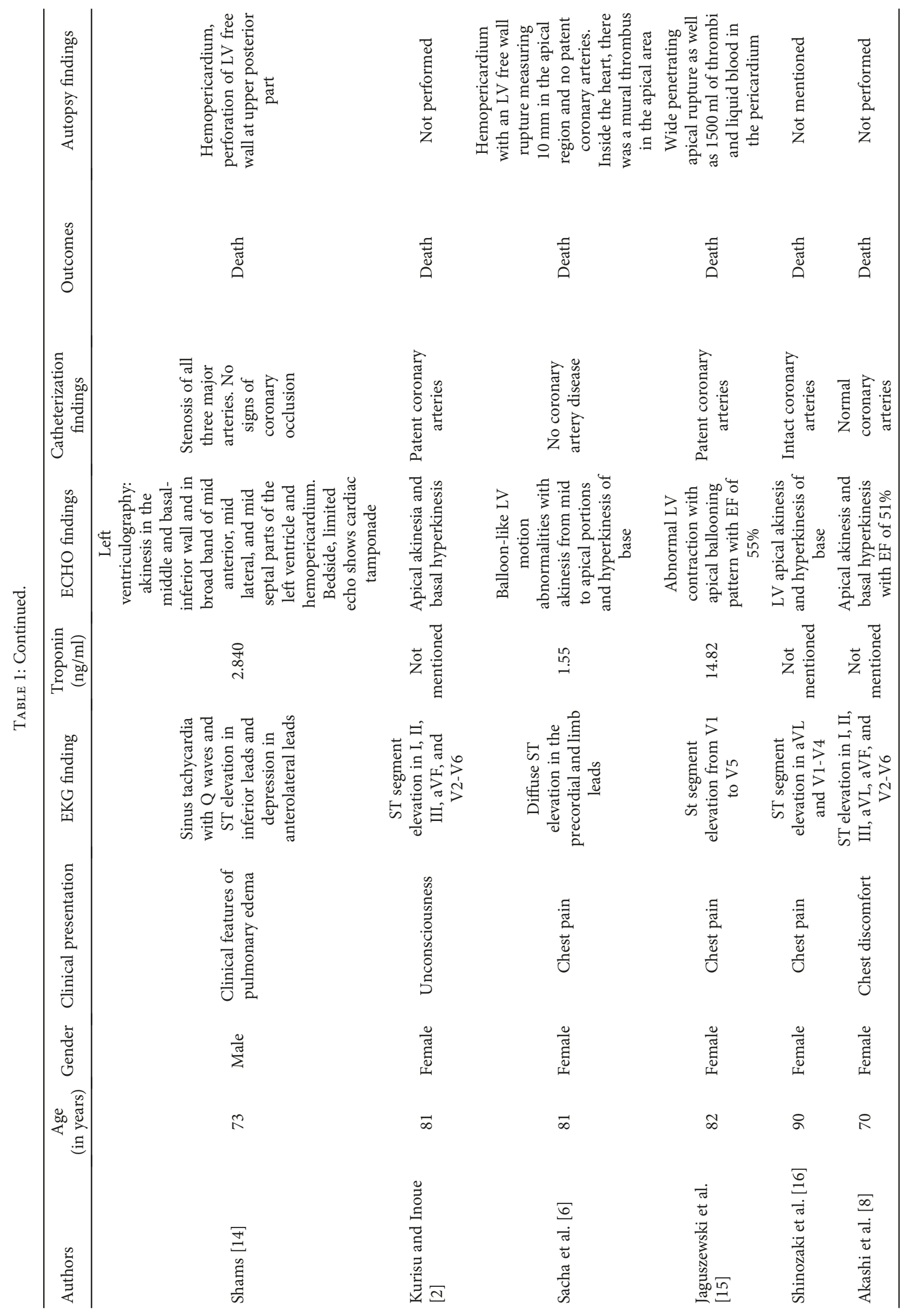




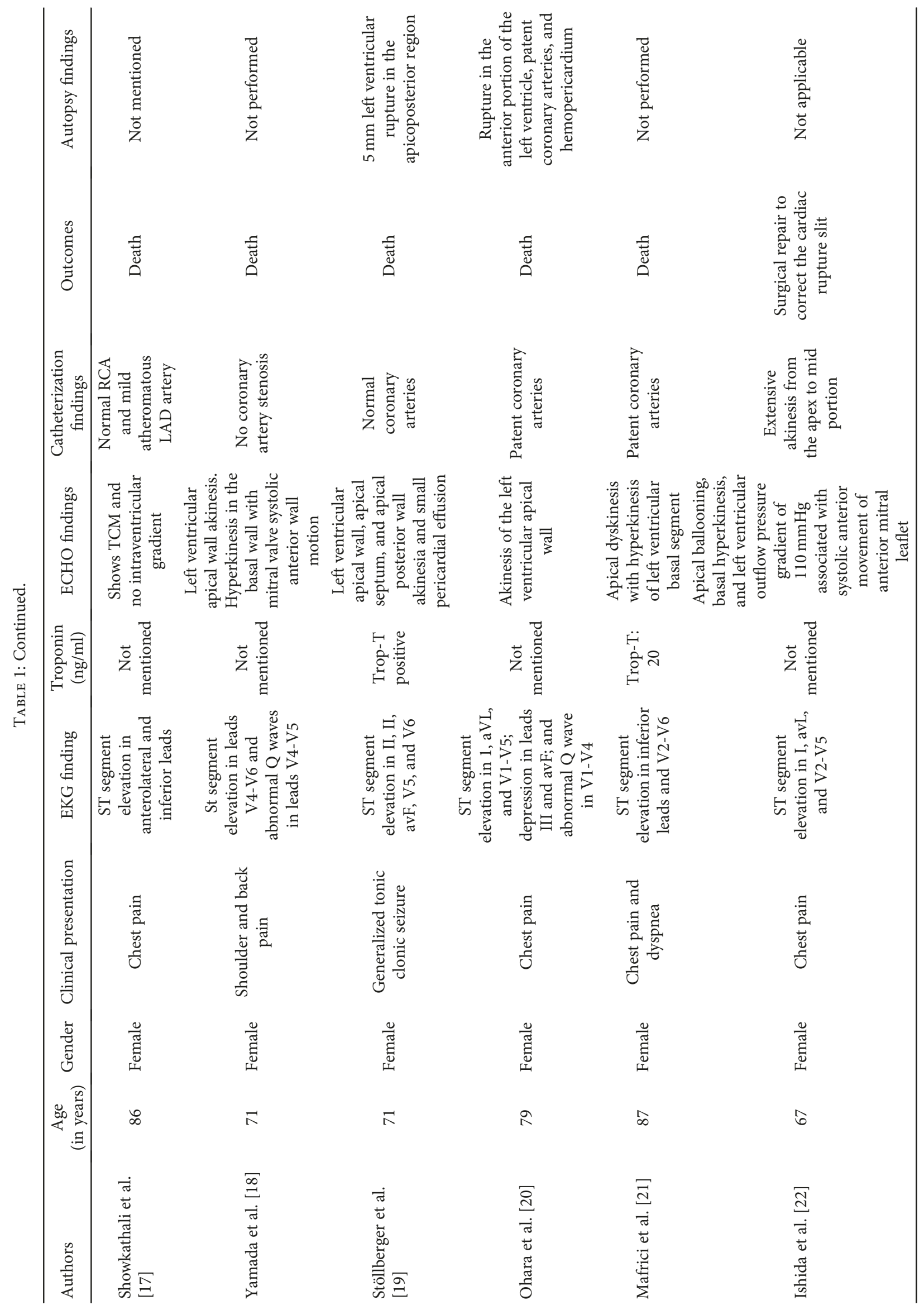




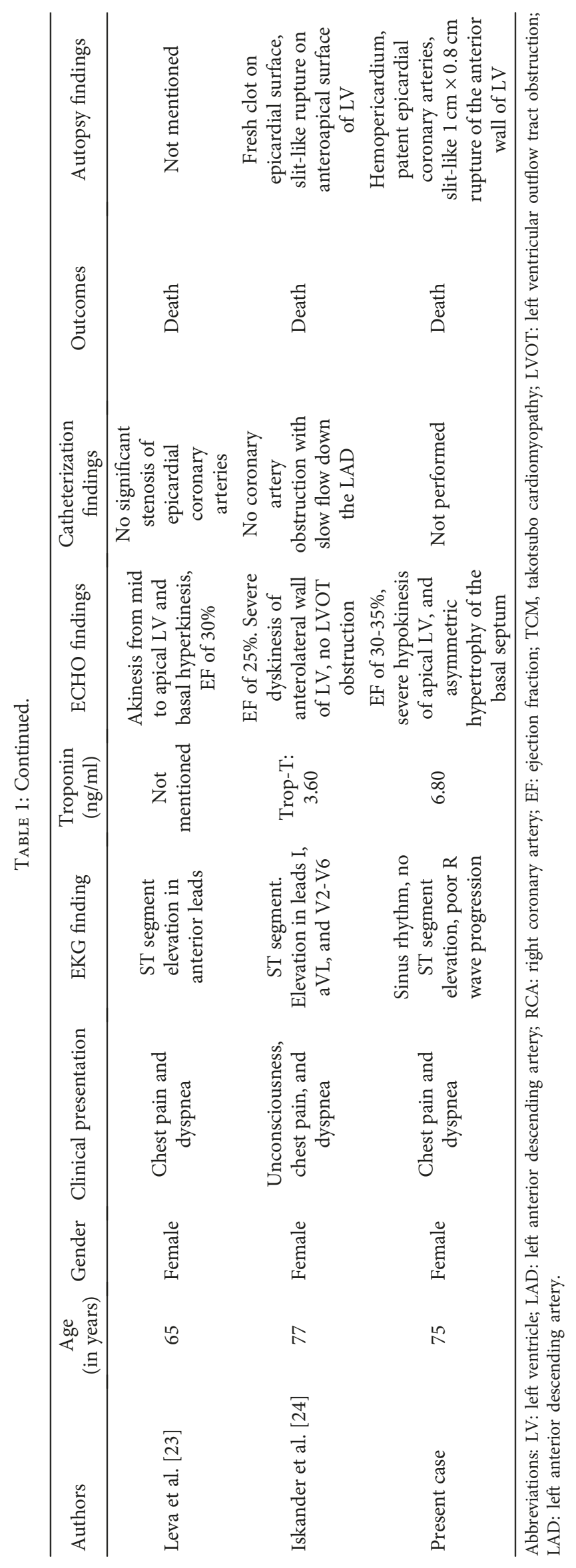


The prognosis of TCM is usually favourable, and left ventricular function improves in the majority of cases with conservative management. Currently, there is no standardised treatment protocol for the patients with TCM [24]. Although beta blockers have been suggested in studies to prevent the progression and recurrence of TCM [16], but recent TCM registry results show no survival benefit with beta blocker [4]. The same registry states that the use of angiotensin receptor blocker or angiotensin-converting enzyme was associated with improved survival [4]. Further studies are needed to delineate the role of beta blockers in TCM. The ST segment elevation in TCM is usually transient and recovers within few days; persistent ST elevation is a warning sign for continued myocardial injury and portend an impending ventricular free wall rupture [24]. The treatment of cardiac rupture in the setting of TCM is surgical repair [11]. It is unclear to date whether anticoagulation plays any role in TCM, but apical thrombus formation had been reported in patients with TCM [8].

\section{Conclusion}

Due to devastating complications of TCM, our case highlights the need for close monitoring of patients with TCM for the first few days. Special consideration should be paid to older female patients as they have higher rates of cardiac rupture.

\section{Conflicts of Interest}

The authors have no conflicts of interest to declare.

\section{Acknowledgments}

We are really thankful to Dr. James L. Fishback (Chancellor's Club Distinguished Teaching Professor (Emeritus), Pathology and Lab Medicine) for his help in interpretation of the pathology slides.

\section{References}

[1] F. Indorato, Y. J. Akashi, C. Rossitto, C. Raffino, and G. Bartoloni, "Takotsubo cardiomyopathy associated with rupture of the left ventricular apex: assessment of histopathological features of a fatal case and literature review," Forensic Science, Medicine, and Pathology, vol. 11, no. 4, pp. 577-583, 2015.

[2] S. Kurisu and I. Inoue, "Cardiac rupture in tako-tsubo cardiomyopathy with persistent ST-segment elevation," International Journal of Cardiology, vol. 158, no. 1, pp. e5-e6, 2012.

[3] K. Singh, K. Carson, Z. Usmani, G. Sawhney, R. Shah, and J. Horowitz, "Systematic review and meta-analysis of incidence and correlates of recurrence of takotsubo cardiomyopathy," International Journal of Cardiology, vol. 174, no. 3, pp. 696-701, 2014.

[4] C. Templin, J. R. Ghadri, J. Diekmann et al., "Clinical features and outcomes of takotsubo (stress) cardiomyopathy," The New England Journal of Medicine, vol. 373, no. 10, pp. 929-938, 2015.

[5] S. Yoshida, K. Miwa, T. Matsubara et al., "Stress-induced takotsubo cardiomyopathy complicated with wall rupture and thrombus formation," International Journal of Cardiology, vol. 161, no. 1, pp. e18-e20, 2012.

[6] J. Sacha, J. Maselko, A. Wester, Z. Szudrowicz, and W. Pluta, "Left ventricular apical rupture caused by takotsubo cardiomyopathy-comprehensive pathological heart investigation," Circulation Journal, vol. 71, no. 6, pp. 982-985, 2007.

[7] D. C. Scantlebury and A. Prasad, "Diagnosis of takotsubo cardiomyopathy," Circulation Journal, vol. 78, no. 9, pp. 2129-2139, 2014.

[8] Y. J. Akashi, T. Tejima, H. Sakurada et al., "Left Ventricular Rupture Associated with Takotsubo Cardiomyopathy," Mayo Clinic Proceedings, vol. 79, no. 6, pp. 821-824, 2004.

[9] S. Kumar, S. Kaushik, A. Nautiyal et al., "Cardiac rupture in takotsubo cardiomyopathy: a systematic review," Clinical cardiology, vol. 34, no. 11, pp. 672-676, 2011.

[10] S. Pasupathy, R. Tavella, and J. F. Beltrame, "Myocardial infarction with nonobstructive coronary arteries (MINOCA): the past, present, and future management," Circulation, vol. 135, no. 16, pp. 1490-1493, 2017.

[11] M. Zalewska-Adamiec, H. Bachórzewska-Gajewska, M. Kozuch, F. Marek, T. Hirnle, and S. Dobrzycki, "Cardiac rupture in takotsubo cardiomyopathy treated surgically," Advances in Interventional Cardiology, vol. 3, pp. 278-279, 2016.

[12] T. Kudaiberdiev, I. Akhmedova, G. Imanalieva et al., "Surgical treatment of left ventricular wall rupture, regarded as a consequence of takotsubo cardiomyopathy," SAGE Open Medical Case Reports, vol. 5, 2017.

[13] J.-M. Sung, S.-J. Hong, I.-H. Chung et al., "Rupture of right ventricular free wall following ventricular septal rupture in takotsubo cardiomyopathy with right ventricular involvement," Yonsei Medical Journal, vol. 58, no. 1, pp. 248-251, 2017.

[14] S. Y-Hassan, "Cardiac rupture in a patient with takotsubo syndrome triggered by acute myocardial infarction: two messages," International Journal of Cardiology, vol. 177, no. 1, pp. 162-165, 2014.

[15] M. Jaguszewski, M. Fijalkowski, R. Nowak et al., "Ventricular rupture in takotsubo cardiomyopathy," European Heart Journal, vol. 33, no. 8, p. 1027, 2012.

[16] K. Shinozaki, A. Tamura, Y. Abe, S. Yano, and J. Kadota, "Left ventricular free wall rupture in takotsubo cardiomyopathy," International Journal of Cardiology, vol. 115, no. 1, pp. E3-E4, 2007.

[17] R. Showkathali, R. Dworakowski, and P. MacCarthy, "Catastrophic ruptured takotsubo cardiomyopathy," Journal of Cardiovascular Medicine, vol. 16, no. 9, pp. 644-645, 2015.

[18] R. Yamada, N. Watanabe, T. Kume et al., "Left ventricular rupture associated with takotsubo-like left ventricular dysfunction (apical ballooning)," Journal of Echocardiography, vol. 4, no. 2, pp. 59-62, 2006.

[19] C. Stöllberger, J. Huber, B. Enzelsberger, and J. Finsterer, "Fatal outcome of epileptic seizure-induced takotsubo syndrome with left ventricular rupture," European Journal of Neurology, vol. 16, no. 6, pp. e116-e117, 2009.

[20] Y. Ohara, Y. Hiasa, S. Hosokawa et al., "Left ventricular free wall rupture in transient left ventricular apical ballooning," Circulation Journal, vol. 69, no. 5, pp. 621-623, 2005.

[21] A. Mafrici, R. Proietti, R. Fusco, A. De Biase, and S. Klugmann, "Left ventricular free wall rupture in a Caucasian female with takotsubo syndrome: a case report and a brief literature 
review," Journal of Cardiovascular Medicine, vol. 7, no. 12, pp. 880-883, 2006.

[22] T. Ishida, T. Yasu, K. Arao, M. Kawakami, and M. Saito, "Bedside diagnosis of cardiac rupture by contrast echocardiography," Circulation, vol. 112, no. 24, pp. e354-e355, 2005.

[23] R. Ieva, M. Correale, N. D. Brunetti, and M. Di Biase, "A "bad" case of tako-tsubo syndrome," Journal of Thrombosis and Thrombolysis, vol. 28, no. 2, pp. 248-251, 2009.

[24] M. Iskander, A. Abugroun, K. Shehata, F. Iskander, and A. Iskander, "Takotsubo cardiomyopathy-induced cardiac free wall rupture: a case report and review of literature," Cardiology Research, vol. 9, no. 4, pp. 244-249, 2018. 


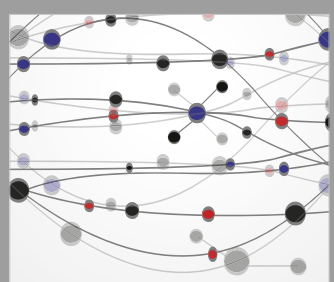

The Scientific World Journal
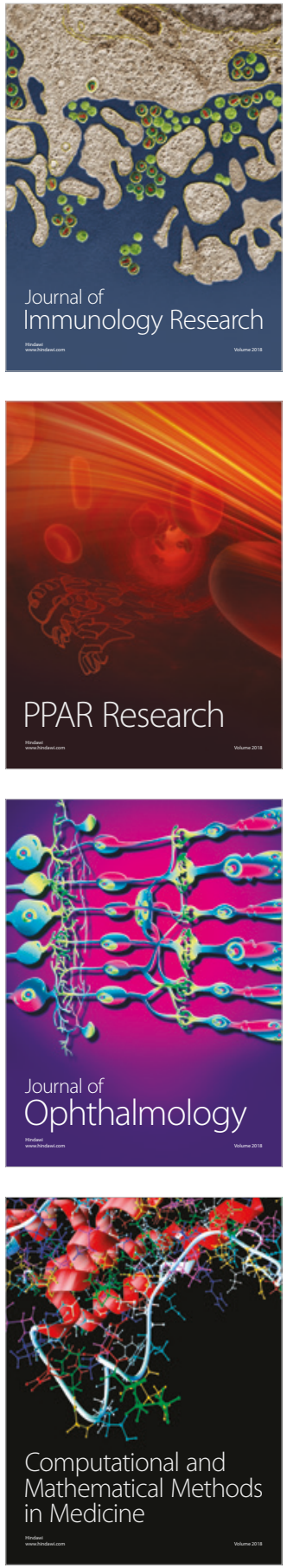

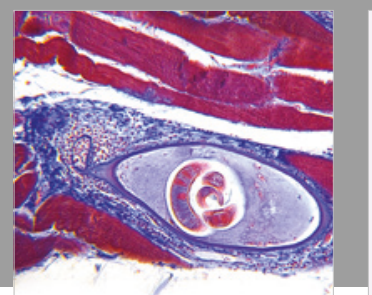

Gastroenterology Research and Practice

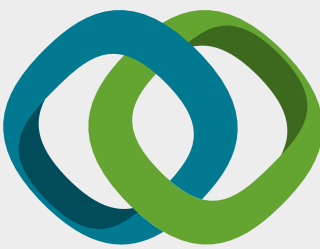

\section{Hindawi}

Submit your manuscripts at

www.hindawi.com
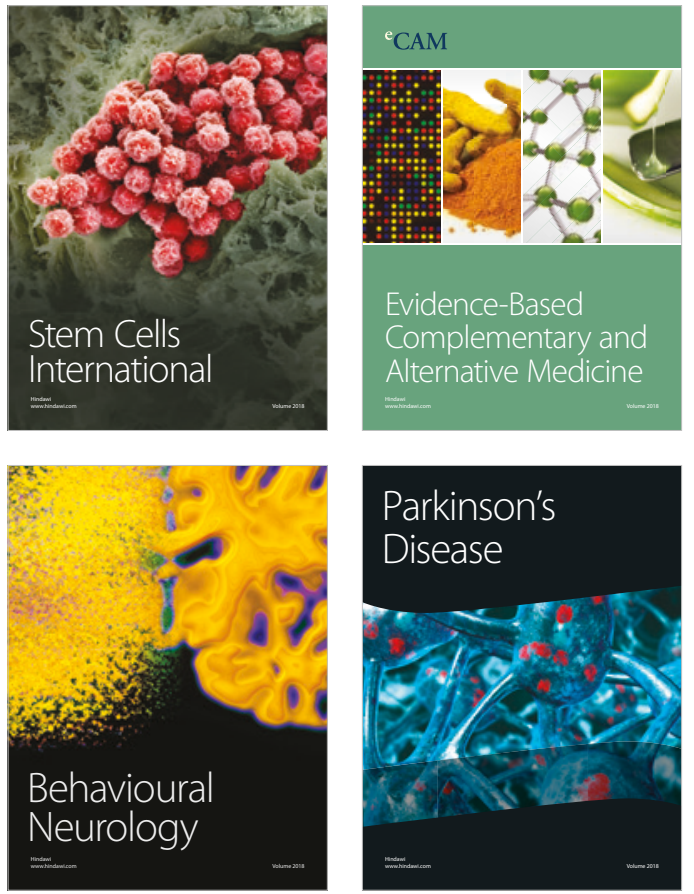

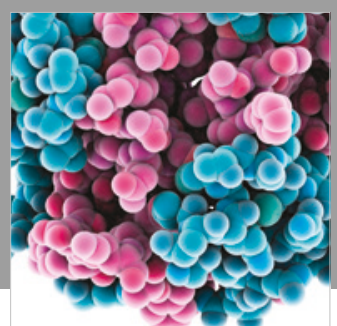

ournal of

Diabetes Research

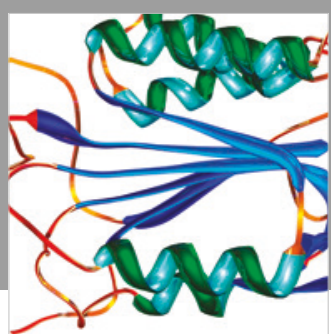

Disease Markers
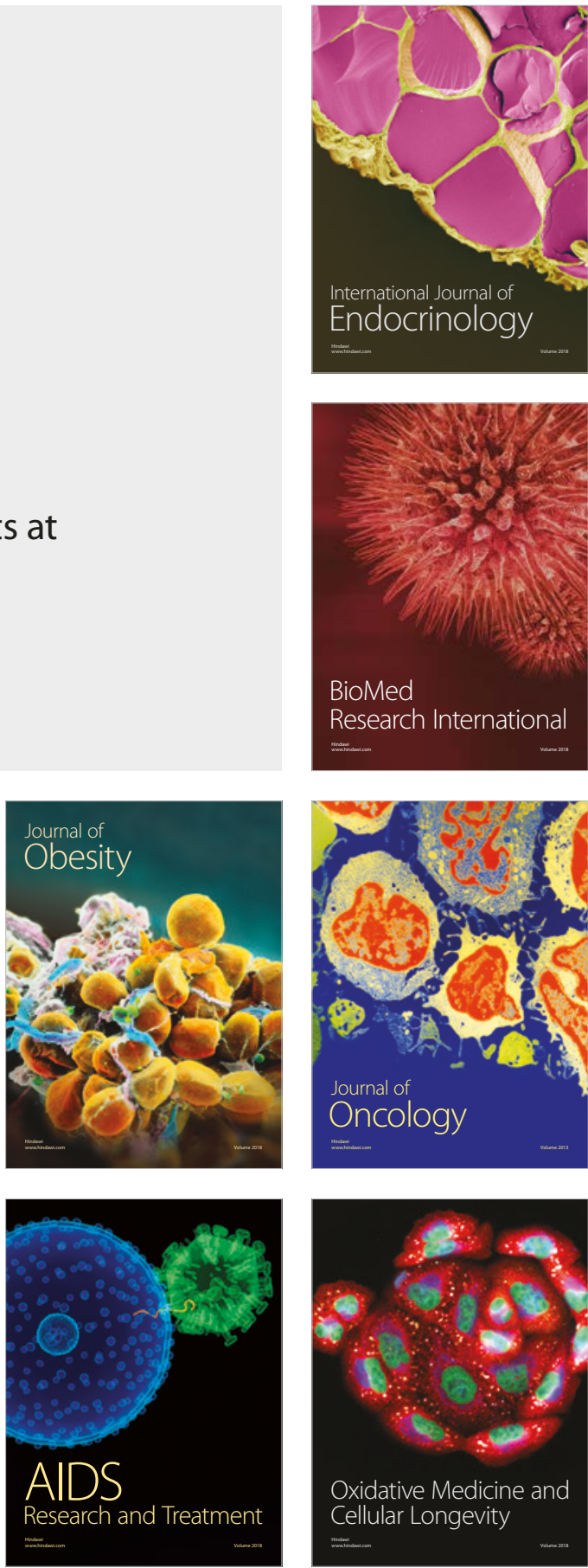